\title{
Nutritional Benefit of Remnant Gastric Preservation in Patients with Esophageal Cancer Undergoing Radical Esophagectomy and Right Colon Interposition
}

\author{
Junya Kitadani \\ Wakayama Medical University \\ Toshiyasu Ojima ( $\nabla$ tojima@wakayama-med.ac.jp ) \\ Wakayama Medical University \\ Keiji Hayata \\ Wakayama Medical University \\ Taro Goda \\ Wakayama Medical University \\ Akihiro Takeuchi \\ Wakayama Medical University \\ Masahiro Katsuda \\ Wakayama Medical University \\ Shinta Tominaga \\ Wakayama Medical University \\ Naoki Fukuda \\ Wakayama Medical University \\ Tomoki Nakai \\ Wakayama Medical University \\ Shotaro Nagano \\ Wakayama Medical University \\ Hiroki Yamaue \\ Wakayama Medical University
}

\section{Research Article}

Keywords: esophageal cancer, esophagectomy, colon interposition

Posted Date: February 28th, 2022

DOI: https://doi.org/10.21203/rs.3.rs-1375516/v1 
License: (c) (i) This work is licensed under a Creative Commons Attribution 4.0 International License. Read Full License 


\section{Abstract \\ Background}

This retrospective study aimed to investigate the short-term surgical outcomes and nutritional status of right colon interposition in patients with esophageal cancer who could not undergo gastric tube reconstruction.

\section{Methods}

64 patients underwent subtotal esophagectomy with reconstruction using right colon interposition for esophageal cancer at Wakayama Medical University Hospital between January 2001 and July 2020.

\section{Results}

18 patients had cologastrostomy and 46 patients had colojejunostomy. The median operation time in the cologastorostomy group was significantly shorter than that in the colojejunostomy group (494 minutes vs. 600 minutes; $P=0.0013$ ). And, the median amount of blood loss in the cologastrostomy group was significantly less than that in the colojejunostomy group ( $209 \mathrm{ml} v \mathrm{vs} .485 \mathrm{ml} ; P=0.037)$. The perforation of colon graft was observed in 3 patients ( $7 \%)$ and colon graft necrosis was observed in 1 patient $(2 \%)$ were each observed in the gastrojejunostomy group. Median body weight change in one year after surgery in the cologastrostomy group was significantly less than that of the colojejunostomy group (93.6\% vs. $86.8 \% ; P=0.041)$. Further, each of median serum total protein level and serum albumin level in one year after surgery in the cologastrostomy group was significantly higher than that of the colojejunostomy group $(7.0 \mathrm{~g} / \mathrm{dL}$ vs. $6.5 \mathrm{~g} / \mathrm{dL}, P=0.024,3.9 \mathrm{~g} / \mathrm{dL}$ vs. $3.6 \mathrm{~g} / \mathrm{dL}, P=0.045)$.

\section{Conclusions}

Subtotal esophagectomy with reconstruction using right colon interposition is a safe and feasible procedure for the patients with esophageal cancer in whom gastric tubes cannot be used.

Cologastrostomy with preserving remnant stomach had benefits of the surgical outcomes and the postoperative nutritional status.

\section{Introduction}

Esophageal cancer is the fifth leading cause of cancer-related death for men and the eighth for women worldwide [1]. Although esophagectomy with a two- or three-field lymph node dissection is still considered to be a potentially curative treatment, it is highly invasive and there is a high rate of morbidity, despite improvements in surgical technique and postoperative management [2-5]. Gastric tubes are generally used for the reconstruction after esophagectomy, they provide abundant blood flow and can be 
safely pulled-up to the neck [6, 7]. However, in cases with a previous history of gastrectomy, or with synchronous gastric cancer, gastric conduit cancer, or with loss of a gastric tube, instead of the stomach, colon interposition or pedicled jejunal flap reconstruction with microvascular anastomosis (MVA) are performed [8-23]. In our institute, right colon interposition is the first choice when gastric tube reconstruction is not possible. Advantages of right colon interposition are that Bauhin valve prevents regurgitation, there is a reservoir-like capacity in the cecum, and the closeness of the diameter of the terminal ileum and esophagus [24]. On the other hand, there are disadvantages including many variations of mesenteric blood vessels, which may cause ischemia, and a comparatively more complicated procedure with multiple anastomoses [22]. There is currently no consensus as to whether MVA should be routinely performed. In previous reports, colon interposition with MVA was not particularly less likely to result in anastomotic leakage $[15,19]$. We have therefore adopted right colon interposition without MVA. Series of subtotal esophagectomy with reconstruction using right colon interposition without MVA for esophageal cancer have not been widely reported $[10,14,16,25]$. This retrospective study aims to investigate the short-term surgical outcomes of right colon interposition in patients with esophageal cancer who cannot undergo gastric tube reconstruction. In particular, we investigated the effect of cologastrostomy on the nutritional status when the residual stomach could be preserved.

\section{Materials And Methods}

\section{Patients}

This retrospective cohort study was conducted at the Wakayama Medical University Hospital (WMUH), Wakayama, Japan. This study was in agreement with the guidelines of the institutional ethics committee (approval number 3291) and was conducted in accordance with the Declaration of Helsinki. 64 patients underwent subtotal esophagectomy with reconstruction using right colon interposition for esophageal cancer at WMUH between January 2001 and July 2020. All consecutive patients were included in this retrospective study. Clinicopathologic factors were evaluated retrospectively based on hospital records, including age, sex, history of gastrectomy, type of previous gastrectomy and surgical factors including operation time and blood loss. Branches of the superior mesenteric artery including the right colic artery and the ileocolic artery (ICA) were evaluated using dynamic computed tomography (CT). Clinical and pathological stages were determined according to the TNM classification (UICC 8th edition) [26]. The severity of the postoperative complications after operation was estimated according to the Clavien-Dindo classification [27].

\section{Surgical procedures}

Until May 2010, 38 patients underwent open right transthoracic esophagectomy with two-field (total mediastinal, perigastric and coeliac regions) or three-field (adding supraclavicular and cervical paratracheal regions) lymph node dissections. The subsequent 26 patients underwent minimally-invasive thoracoscopic esophagectomy $[5,28]$. The esophagus is transected with a linear stapler in the thoracic cavity depending on the location of the tumor. A midline incision is made in the upper abdomen to 
remove the section of the esophagus containing the tumor. Kocher mobilization is performed to mobilize the duodenum and right colon from the retroperitoneum. The appendix is removed to prevent appendicitis. The colon interposition was performed as the following principles: (i) use the right hemicolon; (ii) preserve the right colic artery, as well as the right branch of the middle colic artery; (iii) dissect the ICA; (iv) trim the mesentery along the marginal vessels and transect the ileum with a linear stapler $20 \mathrm{~cm}$ from the ileum end; (v) lift the graft in the retrosternal route; (vi) do not perform supercharge or superdrainage unless the blood flow in the graft is clearly poor; (vii) anastomose cervical esophagus and ileum at the neck, and the remnant stomach and colon (Fig. 1a), or the jejunum and colon (Fig. 1b); (viii) anastomose the anal-side transverse colon and ileum; (ix) insert a $16 \mathrm{Fr}$ nasal tube into the colon graft and a $12 \mathrm{Fr}$ feeding tube into the jejunum $30 \mathrm{~cm}$ from the Treitz ligament. Until 2012, all patients underwent total gastrectomy and colojejunostomy. On the other hand, after 2013, the patients were intentionally stomach-preserving and underwent cologastrostomy.

\section{Nutritional status and follow-up}

Food intake was usually started on the 8th day if there were no anastomotic leakage or severe dysphagia. Nutrition through a feeding jejunostomy or a feeding gastrostomy was continued for an average of 3 months until enough food intake was achieved. Follow-up was conducted every three months to measure body weight change, serum total protein and albumin values. Follow-up included systematical clinical examination and thoraco-abdominal dynamic CT scan and upper endoscopy every six month.

\section{Statistical analyses}

All statistical analyses were carried out using the JMP Pro 14.1 (SAS Institute Inc., Cary, NC, USA). Categorical variables were assessed using Chi square method. Continuous variables were evaluated using the Wilcoxon signed-rank test. Statistical significance was defined as a $P$ value $<0.05$.

\section{Results}

\section{Patient characteristics}

Total 64 patients who underwent right colon interposition in patients with esophageal cancer were eligible for this retrospective study, of which,18 patients had cologastrostomy (Fig. 1a) and 46 patients had colojejunostomy (Fig. 1b). Cologastorostomy and colojejunostomy were performed via hand sewn or functional end to end anastomosis. Table 1 showed the comparison of patient characteristics between the cologastorostomy group between the colojejunostomy group. Age, gender, location of esophageal tumor, pathological stage, receiving neoadjuvant therapy had no significant difference. There were more history of total gastrectomy and synchronous disease in the colojejunostomy group than that in the cologastrostomy group $(P=0.0002)$. 
Table 1

Comparison of patient characteristics between the Cologastrostomy group and Colojejunostomy group

\section{Categories}

Age, median, years

Gender

Male

Female

Location of esophageal tumor

Ut

Mt

$\mathrm{Lt}$

$\mathrm{Ae}$

pStage (TNM classification 8th

edition)

0

I

II

III

IV

18)

Colojejunostomy

0.254
$1(6 \%)$

$15(83 \%)$

$2(11 \%)$

$0(0 \%)$

$69.5(52-84)$

$18(100 \%)$

$0(0 \%)$

group $(n=46)$

$68(56-81)$

0.129

0.513

$44(96 \%)$

$2(4 \%)$

$3(6 \%)$

$27(59 \%)$

$15(33 \%)$

$1(2 \%)$

value

0.121

$1(2 \%)$

$9(20 \%)$

7 (39\%)

$10(22 \%)$

$6(33 \%)$

$21(46 \%)$

$3(16 \%)$

$5(10 \%)$
Neoadjuvant therapy

0.876

$4(22 \%)$

$8(17 \%)$

$1(6 \%)$

$2(5 \%)$

$13(72 \%)$

$36(78 \%)$

None

History of gastrectomy

Total gastrectomy

$0(0 \%)$

$7(15 \%)$

Distal gastrectomy

$17(94 \%)$

$1(6 \%)$
$17(37 \%)$

$22(48 \%)$
Synchronous gastric cancer or ulcer

$U t$ upper thoracic esophagus, $M t$ middle thoracic esophagus, $L t$ lower thoracic esophagus, $A e$ abdominal esophagus 
Comparison of surgical outcomes between the cologastrostomy group and colojejunostomy group were shown in Table 2. The median operation time in the cologastorostomy group was significantly shorter than that in the colojejunostomy group (494 minutes vs. 600 minutes; $P=0.0013$ ). And, the median amount of blood loss in the cologastorostomy group was significantly less than that in the colojejunostomy group (209 $\mathrm{ml}$ vs. $485 \mathrm{ml} ; P=0.037$ ). In all cases, right colon interposition was performed through the retrosternal route. The right colic artery was present in 26 patients (40\%) and was preserved in these cases. No patients were performed MVA. There were no differences of the complications with higher than Clavien-Dindo grade II or those with higher than Clavien-Dindo grade IIla between the cologastrostomy group and colojejunostomy group. Early or late perforation of colon graft was observed in 3 patients $(7 \%)$ and colon graft necrosis was observed in 1 patient $(2 \%)$ were each observed in the gastrojejunostomy group. Two patients in the gastrojejunostomy group had graft loss, and both underwent second-stage jejunal reconstruction. There was no mortality in our consecutive series. The median post-operative hospital stay was not significantly different between the cologastrostomy group and the colojejunostomy group ( 29 days vs. 29 days; $P=0.307$ ). 
Table 2

Comparison of surgical outcomes between the Cologastrostomy group and Colojejunostomy group

\begin{tabular}{|c|c|c|c|}
\hline Categories & $\begin{array}{l}\text { Cologastrostomy group }(n= \\
18)\end{array}$ & $\begin{array}{l}\text { Colojejunostomy } \\
\text { group }(n=46)\end{array}$ & $\begin{array}{l}P \\
\text { value }\end{array}$ \\
\hline Operation time, median, min & $494(363-622)$ & $600(295-860)$ & 0.0013 \\
\hline Blood loss, median, ml & $209(50-685)$ & $485(35-1500)$ & 0.037 \\
\hline Lymph node dissection & & & 0.272 \\
\hline Two-field & $13(72 \%)$ & $26(57 \%)$ & \\
\hline Three-field & $5(28 \%)$ & $20(43 \%)$ & \\
\hline Reconstruction route & & & 1.000 \\
\hline Retrosternal & $18(100 \%)$ & $46(100 \%)$ & \\
\hline Posterior mediastinum & $0(0 \%)$ & $0(0 \%)$ & \\
\hline Percutaneous & $0(0 \%)$ & $0(0 \%)$ & \\
\hline Anastomosis method (neck) & & & 0.068 \\
\hline Hand sewn anastomosis & $2(11 \%)$ & $10(22 \%)$ & \\
\hline Circular stapler & $7(39 \%)$ & $27(59 \%)$ & \\
\hline Functional end to end anastomosis & $9(50 \%)$ & $9(19 \%)$ & \\
\hline \multicolumn{4}{|l|}{ Postoperative complications } \\
\hline Overall morbidity & $10(55 \%)$ & $32(69 \%)$ & 0.289 \\
\hline \multicolumn{4}{|l|}{$(C-D$ grade $\geqq 2)$} \\
\hline Overall morbidity & $7(39 \%)$ & $28(61 \%)$ & 0.112 \\
\hline \multicolumn{4}{|l|}{$(C-D$ grade $\geqq 3 a)$} \\
\hline Anastomotic leakage & $2(11 \%)$ & $7(15 \%)$ & 1.000 \\
\hline Anastomotic stenosis & $4(22 \%)$ & $19(41 \%)$ & 0.246 \\
\hline Respiratory complications & $2(11 \%)$ & $9(20 \%)$ & 0.713 \\
\hline Recurrent nerve paralysis & $3(17 \%)$ & $8(17 \%)$ & 1.000 \\
\hline lleus & $0(0 \%)$ & $2(4 \%)$ & 1.000 \\
\hline Reconstructive colon perforation & $0(0 \%)$ & $3(7 \%)$ & 0.553 \\
\hline Reconstructive colon necrosis & $0(0 \%)$ & $1(2 \%)$ & 1.000 \\
\hline
\end{tabular}




\begin{tabular}{|c|c|c|c|}
\hline Categories & $\begin{array}{l}\text { Cologastrostomy group }(n= \\
\text { 18) }\end{array}$ & $\begin{array}{l}\text { Colojejunostomy } \\
\text { group }(n=46)\end{array}$ & $\begin{array}{l}P \\
\text { value }\end{array}$ \\
\hline Hernia of the graft & $0(0 \%)$ & $1(2 \%)$ & 1.000 \\
\hline Graft loss & $0(0 \%)$ & $2(4 \%)$ & 1.000 \\
\hline Arrhythmia & $1(6 \%)$ & $3(7 \%)$ & 1.000 \\
\hline Chylothorax & $1(6 \%)$ & $1(2 \%)$ & 0.487 \\
\hline Pneumothorax & $1(6 \%)$ & $2(4 \%)$ & 1.000 \\
\hline Mortality & $0(0 \%)$ & $0(0 \%)$ & 1.000 \\
\hline $\begin{array}{l}\text { Post-operative hospital stays, median, } \\
\text { days }\end{array}$ & $29(20-49)$ & $29(16-250)$ & 0.307 \\
\hline \multicolumn{4}{|l|}{$C-D$ Clavien-Dindo classification } \\
\hline
\end{tabular}

Nutritional comparisons about body weight change, serum total protein level and serum albumin level at one year after esophagectomy and colon interposition between the cologastrostomy group and the colojejunostomy group were shown in Fig. 2.

Median body weight change in one year after surgery in the cologastrostomy group was significantly less than that of the colojejunostomy group (93.6\% vs. $86.8 \% ; P=0.041)$.

Further, each of median serum total protein level and serum albumin level in one year after surgery in the cologastrostomy group was significantly higher than that of the colojejunostomy group $(7.0 \mathrm{~g} / \mathrm{dL}$ vs. $6.5 \mathrm{~g} / \mathrm{dL} ; P=0.024,3.9 \mathrm{~g} / \mathrm{dL}$ vs. $3.6 \mathrm{~g} / \mathrm{dL} ; P=0.045)$.

\section{Discussion}

This retrospective study showed that esophagectomy and right colon interposition without MVA for patients with esophageal cancer was feasible and safe and without mortality. Cologastrostomy with preserving remnant stomach had benefits of short operation time, a little amount of intraoperative blood loss and postoperative good nutritional status.

The rate of anastomotic leakage in our study was $14 \%$, which was similar to the previously reported rate of anastomotic leakage in colon interposition with MVA $[8,12,15,19]$. In our series, the retrosternal route was always selected so that the distance of the reconstruction route would be as short as possible. In addition, the retrosternal route has better cosmetic results than the subcutaneous route. Our previous study proved that the postoperative anastomotic leakage was independent prognostic factor in right 
colon interposition for the patients with esophageal cancer [29]. Although there were no differences of the complications between the cologastrostomy group and the colojejunostomy group, very critical complications as perforation and necrosis of colon graft were not observed in the cologastrostomy group. This reason was considered why preserving remnant stomach prevented from abnormal expansion of colon graft. If gastrectomy for gastric cancer was preceded, the lymph node dissection of the lesser curvature side and the supra-pancreatic area has already been completed. If the previous surgery is performed for a benign disease or a simultaneous ulcer, we think that only lymph node dissection should be added. There was no difference in recurrence rate and survival rate between the total gastrectomy group and the remnant stomach-preservation group in this study (data not shown).

Nutritional status about body weight change, serum total protein level and serum albumin level at one year after esophagectomy and colon interposition in the cologastrostomy group were better than those in the gastrojejunostomy group. In the surgical procedure for gastric cancer, total gastrectomy has been shown in the previous reports to have disadvantages regarding nutritional status, including body weight loss [30, 31]. Furthermore, the remnant stomach may be associated with postoperative appetite stimulation because gut hormones as ghrelin are secreted [30,32].

In cases when gastric tube reconstruction could not peformed, no clinical trials have yet ascertained whether colon interposition or pedicled jejunal flap reconstruction is better $[8-10,12-25,33]$. Pedicled jejunal flap reconstruction may be a promising procedure because fewer anastomoses are needed than in colon interposition. Creating a sufficient length of jejunal graft is sometimes difficult, however, especially in obese patients [22]. Surgical outcomes and quality of life of colon interposition and jejunal reconstruction will be examined in a prospective cohort study based in multiple centers.

Several limitations associated with this study warrant mention. First, if the previous surgery was total gastrectomy, or if simultaneous gastric cancer required total gastrectomy, the stomach could not be preserved inevitably. The patients were allocated to the two groups according to the sequential nature of the surgery. Secondly, the number of patients with esophageal cancer in whom gastric tubes could not be used was relatively small, so only a small number of patients were eligible for this retrospective study, which was based in a single center. A prospective study will overcome the limitations of the retrospective design and selection bias.

\section{Conclusion}

Subtotal esophagectomy with reconstruction using right colon interposition is a safe and feasible procedure for the patients with esophageal cancer in whom gastric tubes cannot be used.

Cologastrostomy with preserving remnant stomach had benefits of the surgical outcomes and the postoperative nutritional status.

\section{Abbreviations}


MVA

microvascular anastomosis

WMUH

Wakayama Medical University Hospital

ICA

ileocolic artery

CT

computed tomography

\section{Declarations}

\section{Ethics approval and consent to participate}

This study was approved by the Wakayama Medical University Institutional Review Board. All procedures were undertaken in accordance with the ethical standards of the responsible committee on human experimentation (institutional and national) and with the Helsinki Declaration of 1964 and later versions. Informed consent to be included in the study, or the equivalent, was obtained from all patients.

\section{Consent for publication}

Not applicable.

\section{Competing Interests}

The authors declare no competing interests.

\section{Funding}

There are no funding resources to be reported or declared.

\section{Authors' Contributions}

JK designed the study and wrote the initial draft of the manuscript. JK and TO contributed to data interpretation and critical revision of the manuscript. All the other authors $(\mathrm{KH}, \mathrm{TG}, \mathrm{AT}, \mathrm{MK}, \mathrm{ST}, \mathrm{NF}, \mathrm{TN}, \mathrm{SN}$ and $\mathrm{HY}$ ) contributed to data collection and interpretation and critical review of the manuscript. All authors have read and approved the final version of the manuscript and have agreed to be accountable for all aspects of the study, ensuring that any queries related to the accuracy or integrity of any part of the work are answerable.

\section{Data availability / Availability of Data and Materials statement}

The datasets generated and/or analyzed during the current study are not publicly available due to hospital regulations but are available from the corresponding author on reasonable request. 


\section{Acknowledgments}

We acknowledge proofreading and editing by Benjamin Phillis from the Clinical Study Support Center at Wakayama Medical University.

\section{References}

1. Jemal A, Bray F, Center MM, Ferlay J, Ward E, Forman D. Global cancer statistics. CA Cancer J Clin. 2011;61(2):69-90.

2. Lagarde SM, Reitsma JB, Maris AK, et al. Preoperative prediction of the occurrence and severity of complications after esophagectomy for cancer with use of a nomogram. Ann Thorac Surg. 2008;85(6):1938-45.

3. Lerut T, Moons J, Coosemans W, et al. Postoperative complications after transthoracic esophagectomy for cancer of the esophagus and gastroesophageal junction are correlated with early cancer recurrence: role of systematic grading of complications using the modified Clavien classification. Ann Surg. 2009;250(5):798-807.

4. Nakamura M, Nakamori M, Ojima T, et al. The effects of rikkunshito on body weight loss after esophagectomy. J Surg Res. 2016;204(1):130-8.

5. Ojima T, Nakamori M, Nakamura M, et al. Randomized clinical trial of landiolol hydrochloride for the prevention of atrial fibrillation and postoperative complications after oesophagectomy for cancer. $\mathrm{Br}$ J Surg. 2017;104(8):1003-9.

6. Zehetner J, DeMeester SR, Alicuben ET, et al. Intraoperative Assessment of Perfusion of the Gastric Graft and Correlation With Anastomotic Leaks After Esophagectomy. Ann Surg. 2015;262(1):74-8.

7. Nishikawa K, Fujita T, Yuda M, et al. Quantitative Assessment of Blood Flow in the Gastric Conduit With Thermal Imaging for Esophageal Reconstruction. Ann Surg. 2020;271(6):1087-94.

8. Fujita $\mathrm{H}$, Yamana $\mathrm{H}$, Sueyoshi S, et al. Impact on outcome of additional microvascular anastomosissupercharge-on colon interposition for esophageal replacement: comparative and multivariate analysis. World J Surg. 1997;21(9):998-1003.

9. Fürst H, Hüttl TP, Löhe F, Schildberg FW. German experience with colon interposition grafting as an esophageal substitute. Dis Esophagus. 2001;14(2):131-4.

10. Davis PA, Law S, Wong J. Colonic interposition after esophagectomy for cancer. Arch Surg. 2003;138(3):303-8.

11. Popovici Z. A new philosophy in esophageal reconstruction with colon. Thirty-years experience. Dis Esophagus. 2003;16(4):323-7.

12. Shirakawa Y, Naomoto Y, Noma K, et al. Colonic interposition and supercharge for esophageal reconstruction. Langenbecks Arch Surg. 2006;391(1):19-23.

13. Knezević JD, Radovanović NS, Simić AP, et al. Colon interposition in the treatment of esophageal caustic strictures: 40 years of experience. Dis Esophagus. 2007;20(6):530-4. 
14. Motoyama S, Kitamura M, Saito R, et al. Surgical outcome of colon interposition by the posterior mediastinal route for thoracic esophageal cancer. Ann Thorac Surg. 2007;83(4):1273-8.

15. Doki Y, Okada K, Miyata H, et al. Long-term and short-term evaluation of esophageal reconstruction using the colon or the jejunum in esophageal cancer patients after gastrectomy. Dis Esophagus. 2008;21(2):132-8.

16. Mine $S$, Udagawa $H$, Tsutsumi $K$, et al. Colon interposition after esophagectomy with extended lymphadenectomy for esophageal cancer. Ann Thorac Surg. 2009;88(5):1647-53.

17. Klink CD, Binnebösel M, Schneider M, Ophoff K, Schumpelick V, Jansen M. Operative outcome of colon interposition in the treatment of esophageal cancer: a 20-year experience. Surgery. 2010;147(4):491-6.

18. Iwata N, Koike M, Kamei Y, et al. Antethoracic pedicled jejunum reconstruction with the supercharge technique for esophageal cancer. World J Surg. 2012;36(11):2622-9.

19. Saeki H, Morita M, Harada N, et al. Esophageal replacement by colon interposition with microvascular surgery for patients with thoracic esophageal cancer: the utility of superdrainage. Dis Esophagus. 2013;26(1):50-6.

20. Greene CL, DeMeester SR, Augustin F, et al. Long-term quality of life and alimentary satisfaction after esophagectomy with colon interposition. Ann Thorac Surg. 2014;98(5):1713-9; discussion 9-20.

21. Reslinger V, Tranchart H, D'Annunzio E, et al. Esophageal reconstruction by colon interposition after esophagectomy for cancer analysis of current indications, operative outcomes, and long-term survival. J Surg Oncol. 2016;113(2):159-64.

22. Watanabe M, Mine S, Nishida K, Kurogochi T, Okamura A, Imamura Y. Reconstruction after esophagectomy for esophageal cancer patients with a history of gastrectomy. Gen Thorac Cardiovasc Surg. 2016;64(8):457-63.

23. Brown J, Lewis WG, Foliaki A, Clark GWB, Blackshaw G, Chan DSY. Colonic Interposition After Adult Oesophagectomy: Systematic Review and Meta-analysis of Conduit Choice and Outcome. J Gastrointest Surg. 2018;22(6):1104-11.

24. Metzger J, Degen L, Beglinger C, von Flüe M, Harder F. Clinical outcome and quality of life after gastric and distal esophagus replacement with an ileocolon interposition. J Gastrointest Surg. 1999;3(4):383-8.

25. Hamai Y, Hihara J, Emi M, Aoki Y, Okada M. Esophageal reconstruction using the terminal ileum and right colon in esophageal cancer surgery. Surg Today. 2012;42(4):342-50.

26. Brierley JD, Gospodarowicz MK, Wittekind C. TNM classification of malignant tumours: John Wiley \& Sons; 2017.

27. Clavien PA, Barkun J, de Oliveira ML, et al. The Clavien-Dindo classification of surgical complications: five-year experience. Ann Surg. 2009;250(2):187-96.

28. Hayata K, Ojima T, Nakamori M, et al. Neoadjuvant Chemotherapy with Docetaxel, Cisplatin and S-1 for Resectable Advanced Esophageal Cancer. Anticancer Res. 2018;38(9):5267-73. 
29. Kitadani J, Ojima T, Nakamura M, et al. Impact of Anastomotic Leakage on Survival for Patients with Thoracic Esophageal Cancer Performed with Esophagectomy Followed by Right Colon Interposition. J Gastrointest Surg. 2021doi: 10.1007/s11605-021-05196-7.

30. Furukawa H, Kurokawa Y, Takiguchi S, et al. Short-term outcomes and nutritional status after laparoscopic subtotal gastrectomy with a very small remnant stomach for cStage I proximal gastric carcinoma. Gastric Cancer. 2018;21(3):500-7.

31. Jiang X, Hiki N, Nunobe S, et al. Laparoscopy-assisted subtotal gastrectomy with very small remnant stomach: a novel surgical procedure for selected early gastric cancer in the upper stomach. Gastric Cancer. 2011;14(2):194-9.

32. Takiguchi S, Adachi S, Yamamoto K, et al. Mapping analysis of ghrelin producing cells in the human stomach associated with chronic gastritis and early cancers. Dig Dis Sci. 2012;57(5):1238-46.

33. Kawano T, Nishikage T, Kawada K, Nakajima Y, Kojima K, Nagai K. Subcutaneous reconstruction using ileocolon with preserved ileocolic vessels following esophagectomy or in esophageal bypass operation. Dig Surg. 2009;26(3):200-4.

\section{Figures}


Figure.1

a.

b.

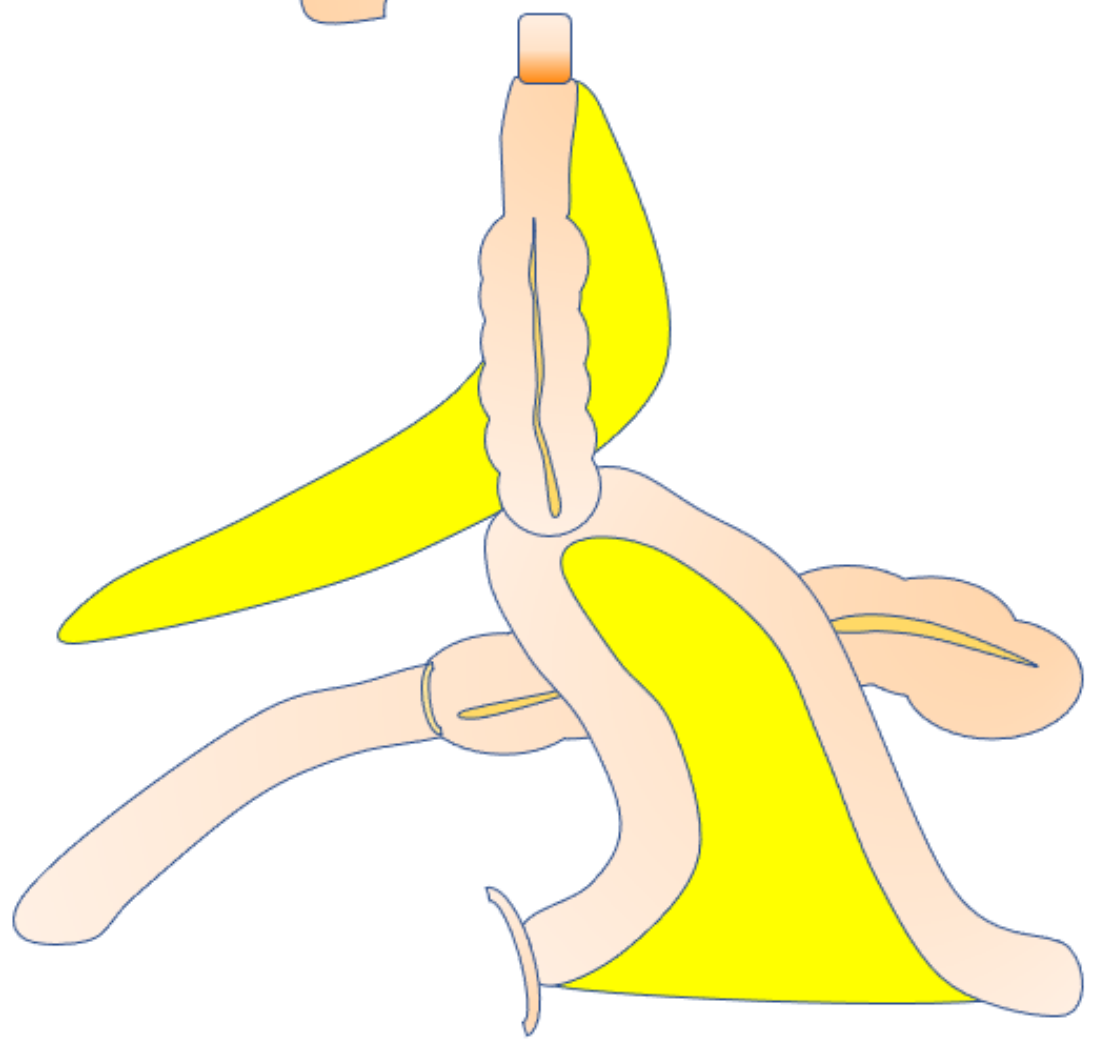

\section{Figure 1}

A schematic illustration of the right colon interposition without MVA through the retrosternal route. (a) Anastomosis of cervical esophagus and ileum at the neck is performed, and if the stomach can be preserved, gastrocolostomy is performed. (b) If the stomach cannot be preserved, ileocolostomy is performed. 
Figure 2

a.

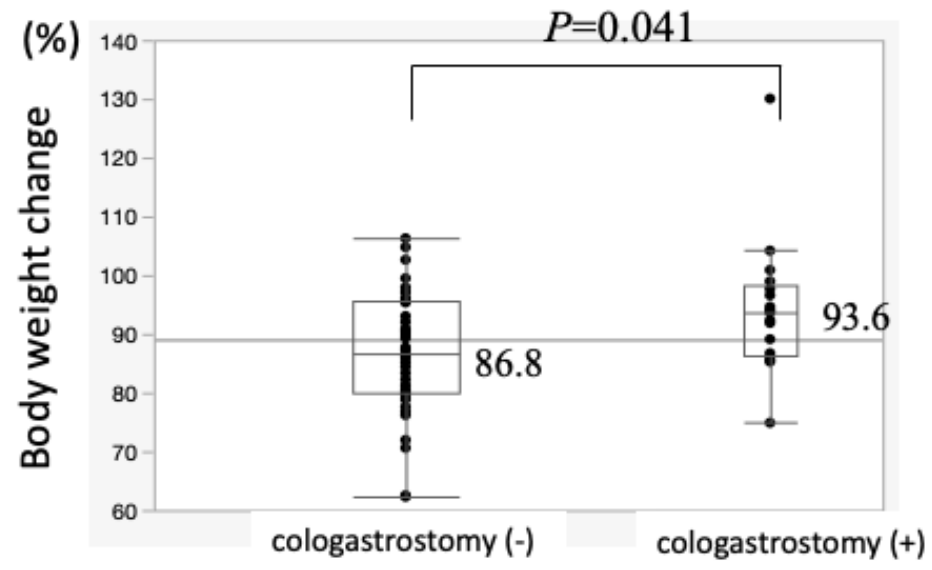

b.

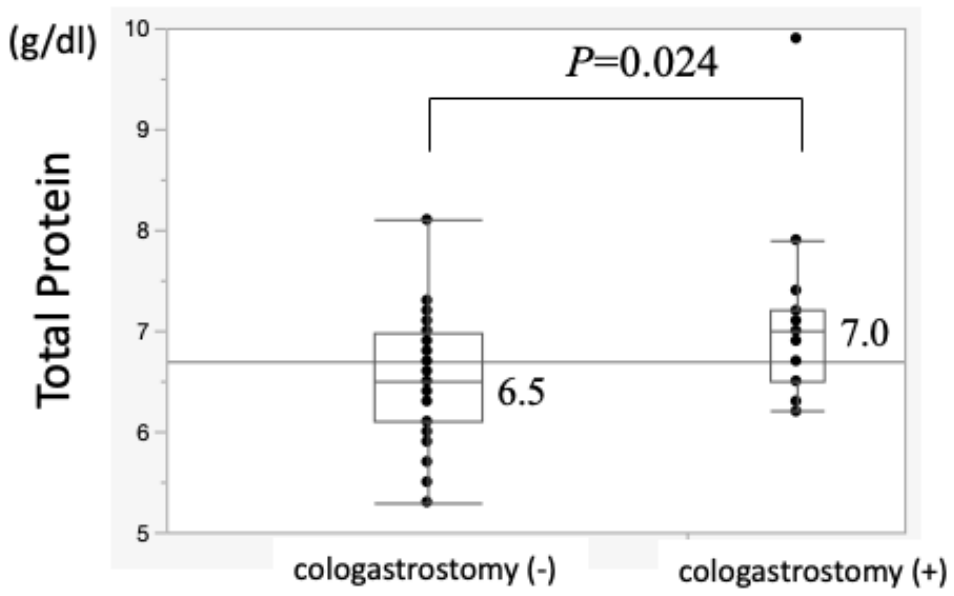

c.

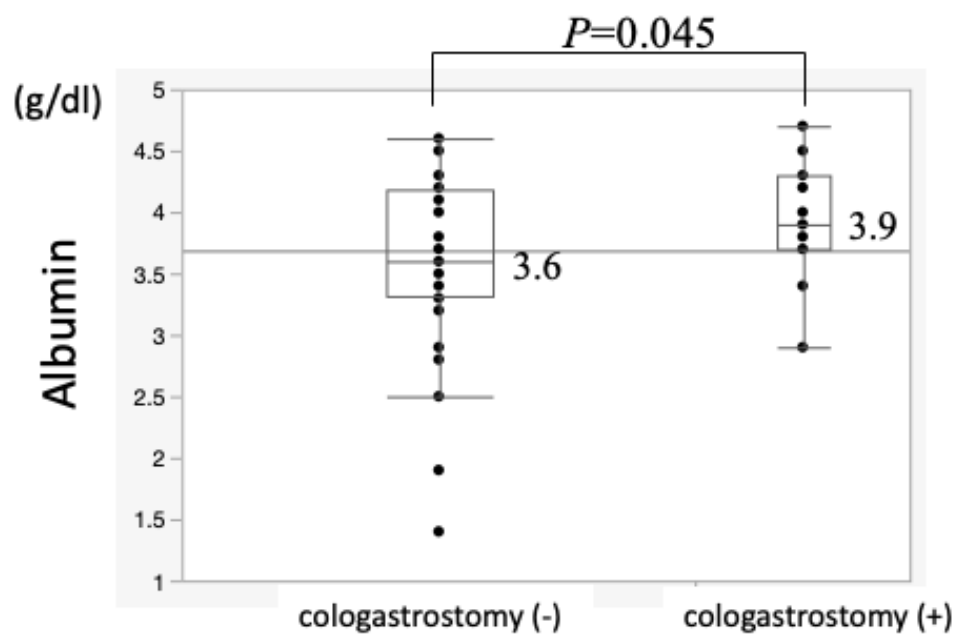

Figure 2

Nutritional comparison between the cologastrostomy group and the colojejunostomy group. (a) Median body weight change in one year after surgery in the cologastrostomy group was significantly less than that of the colojejunostomy group (93.6\% vs. $86.8 \% ; P=0.041)$. (b) Median serum total protein level in one year after surgery in the cologastrostomy group was significantly higher than that of the colojejunostomy group $(7.0 \mathrm{~g} / \mathrm{dL}$ vs. $6.5 \mathrm{~g} / \mathrm{dL} ; P=0.024)$. (c) Median serum albumin level in one year after surgery in the 
cologastrostomy group was significantly higher than that of the colojejunostomy group $(3.9 \mathrm{~g} / \mathrm{dL}$ vs. $3.6 \mathrm{~g} / \mathrm{dL} ; P=0.045)$. 